$10-7-2020$

\title{
The Political Economy of Vermont's Abortion Bill
}

Shishir Shakya

Elham Erfanian

Alexandre R. Scarcioffolo

Follow this and additional works at: https://researchrepository.wvu.edu/rri_pubs

Part of the Models and Methods Commons 


\title{
Regional Research Institute West Virginia University
}

Working Paper Series

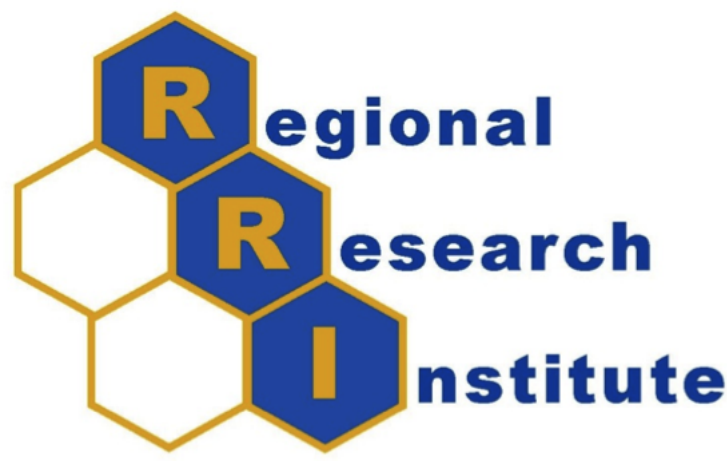

The Political Economy of Vermont's Abortion Bill

\author{
SHISHIR SHAKYA \\ Assistant Professor, Department of Economics, \\ Shippensburg University of Pennsylvania \\ ELHAM ERFANIAN \\ Assistant Professor, Department of Agricultural Economics, \\ UNIVERSITY OF KENTUCKY \\ Alexandre R. Scarcioffolo (Corresponding Author ) \\ Assistant Professor, Department of Economics and Finance, \\ Georgia College \& State University
}

Working Paper Number 2020-04

Date Submitted: October 7, 2020

Keywords: Expressive voting, LASSO, Abortion, Vermont

JEL Classification: D72, D73 


\title{
The Political Economy of Vermont's Abortion Bill
}

\author{
Shishir Shakya* \\ Elham Erfanian $\dagger$ \\ Alexandre R. Scarcioffolo (Corresponding Author ) $\ddagger$
}

October 7, 2020

\begin{abstract}
Public choice literature divides the rationality of voting between instrumental and expressive. In this paper, we take the Vermont legislature in passing the $\mathrm{H}$. 57 bill as a case to explain some of the determinants of expressive voting empirically. The H.57 bill declares that no government entity can interfere with, or restrict, a consenting individual's right to abortion care across the entire gestation period. However, the bill has not changed the previously states quo of the state towards abortion rights. Thus, it creates a situation in which we can analyze the legislator's voting behavior through the lens of expressive voting framework. We utilize a high dimensional dataset and post-double-selection LASSO method to explain the channels that influence the expressive voting on the H. 57 bill. We web scrape the lower and upper chamber voting data on H.57 bill and use the 2017 American Community Survey 5-year estimates to retrieve 89 different socioeconomic, housing, and demographic characteristics of State Legislative Districts. Our results suggest channels of poverty, gender, and population diversity are some crucial mechanisms.
\end{abstract}

\footnotetext{
*Assistant Professor, Department of Economics, Shippensburg University of Pennsylvania, SShakya@ship.edu $\dagger$ Assistant Professor, Department of Agricultural Economics, University of Kentucky, Elham.Erfanian@uky.edu $\ddagger$ Assistant Professor, Department of Economics and Finance, Georgia College \& State University, alexandre.scarcioffolo@gcsu.edu
} 


\section{Introduction}

Public choice literature divides the rationality of voting between instrumental and expressive. The instrumental motivation defines voting as an "investment" to obtain preferred outcomes. In contrast, the expressive motivation ${ }^{1}$ defines voting as an act of "consumption" directly yielding benefits, "akin to 'cheering' or 'booing' at sports events" (Drinkwater and Jennings, 2007). In this paper, we take the Vermont legislature in passing the H. 57 bill -an act to preserve the right to abortion- as a case to empirically explain some of the determinants of expressive voting.

In 2019, Vermont passed an act to preserve the right to abortion (H. 57 bill) across the whole pregnancy period (40 weeks), not limiting until the fetal viability. The bill appears to represent Vermont's legislators' expressive action than an instrumental response since it has not changed the state's status quo (Taylor and Turkewitz, 2020).

Based on the literature, we hypothesize population diversity, education, and poverty are important channels to explain the expressive voting behavior. However, these channels are not randomly assigned. Understanding the link between the channels and voting outcome can be challenging because various confounders can cause both the channels and voting behavior, leading to potential endogeneity. To circumvent endogeneity, we implement the post-double-selection LASSO approach for proper variables selection to block confounding effects in the regression. This approach is based on Neyman-Rubin's potential outcomes but utilizes a machine learning method (LASSO). By utilizing a high dimensional dataset, our results suggest that voter's channels such as education, poverty, and population diversities can influence the voting outcome, contributing to the literature in what drives expressive voting by legislators.

\section{Background and Literature Review}

Abortion rate, defined as abortions per 1,000 women aged 15-44, is an engaging public health indicator of reproductive health that often wrangles with political agendas. In 1973, the United States (U.S.) Supreme Court has recognized the constitutional right to abortion in the Roe vs. Wade decision. ${ }^{2}$

Despite the recent plummeting on abortion rates (Figure 1), there is a crescent wave of restrictions regarding abortion rights in the U.S. For example, Alabama has recently attempted to ban abortion before fetal viability but has been stopped by court order. On the other hand, Vermont has taken an unprecedented step towards supporting abortion rights. In 2019, Vermont passed an act to preserve the right to abortion (H. 57 bill), which states that no government entity can interfere with, or restrict, a consenting individual's right to abortion care. However, the H.57 bill appears to not have changed the state status quo; previously, Vermont possessed no legal limits on when or under what circumstances a woman could decide to end a pregnancy (Taylor and Turkewitz, 2020). The authors go far to argue that H. 57 bill appears to represent more an expressive action of Vermont's legislators than an instrumental decision:

" $(T)$ he bill sends a resonant message to the nation about Vermont's views on abortion rights just as other states are sending far different signals...' In this time when, across the country and nationally, when Roe $v$. Wade and individuals' access to private, reliable reproductive health care and abortion is in question, we thought we'd better be clear in Vermont,' said Ann Pugh, a state representative from South Burlington and one of the Vermont bill's lead sponsors."

Therefore, the vote appears to be purely expressive. From the perspective that the bill seems not to generate significant increments on social gains, but in fact, only express the state's view on abortion rights, creates a situation in which we can isolate the legislator voting behavior through the characteristics of the median voter in their district.

Due to the large discrepancy of state's policies across the U.S., there is a large strand of literature understanding how the composition of each state's population plays a role on shaping the state's view on abortion. For

\footnotetext{
${ }^{1}$ See Greene and Nelson (2002); Copeland and Laband (2002).

${ }^{2}$ Recognized abortion nationwide before the viability of the fetus (after the second trimester). After a fetus becomes viable, States can regulate or outlaw abortions except when necessary to preserve the mother's life or health.
} 
instance, Gohmann and Ohsfeldt (1990); Medoff (2002) indicate that legislator's religion and the district religiosity both can influence voting behavior on abortion bills.

Partisanship contributes to voting behavior. Schecter (2001) found a significant effect of Democrat legislators to vote pro-choice. In contrast, Medoff (2002) suggest that ideology is rather more influential in voting pro-choice. Gender and race also appear to determine voting behavior. Female Republicans tend to deviate from male Republicans voting pro-choice rather than pro-life (Schecter, 2001; Medoff, 2002). Gohmann and Ohsfeldt (1990) highlight the importance of the percentage of women with white-collar jobs in shaping legislator's voting behavior; as the woman's income rises, the cost of childbearing increases. Finally, Strickland and Whicker (1992) suggest that anti-abortionist is more prevalent in states with lower per capita incomes.

\section{Data and Method}

\subsection{Data}

We web scrape Vermont lower and upper chamber voting data on the H.57 bill from the Vermont General Assembly website. This data shows which representatives and senators have voted "Yea" or "Nay". We then use the 2017 American Community Survey 5-year estimates to retrieve 89 different socio, economic, housing, and demographic characteristics of State Legislative Districts. ${ }^{3}$

\subsection{Methodology}

To explain the voting outcomes on H.57, we test three different channels: channel of education, poverty, and diversity of constituents that each legislator represents. However, estimating the impact of these channels in the observational studies demands caution because of endogeneity biases. These channels are not randomly assigned, and experimental manipulation of these channels is infeasible.

Usually, endogeneity may arise via reverse causality, omitted variables, and unobservable factors. However, it's safe to assume there is no reverse causality because each of these channels affects voting behavior, but legislators' voting behavior cannot modify these channels. Secondly, failure to accurately select covariates could lead to omitted variables. In general, economic theory and intuition guide variable selections. In our case, general utilitarian theory and median voters' characteristics could define H.57 voting behavior. However, we do not observe exact data generating processes. Thus we do not have accurate information on which variables to select as proper control on our regressions. Failing to control adequately (under-controlling) can lead to endogeneity through omitted variable bias, and over-controlling could lead to a loss of estimates' efficiency.

To properly control for variable selection, we propose the recently developed technique called post-doubleselection LASSO. Under the unconfoundedness assumption ${ }^{4}$, the post-double-selection LASSO method is more likely to block the endogeneity from omitted variables while avoiding over-fitting.

LASSO is a machine learning algorithm that allows for variable selection. In the simplest form, LASSO is a basic OLS regression that penalizes the regression model's variables for having their coefficient closer to zero (in absolute term). This means that LASSO drops the variables whose coefficients are closer to zero and selects the remaining variables. ${ }^{5}$ However, LASSO alone is just a predictive method and must be adequately adjusted for inference. For this matter, we implement a post-double-selection LASSO estimator.

Belloni et al. (2014) explains the post-double-selection LASSO method as a three steps process. First, run LASSO of the voting outcome on the list of potential control variables to select a set of predictors for the outcome variable. Second, run LASSO of the variable of interest (channels) on the list of possible control variables to pick a set of predictors for the interest channel. The second step is essential because the exclusion of a covariate that is a modest predictor of the dependent variable, but a strong predictor of the channel

\footnotetext{
${ }^{3} \mathrm{~A}$ list of the variables is available upon request.

${ }^{4}$ Channels become as good as random while properly controlling the observables, and there exist not unobservable confounding factors or common causes between channel and voting outcome.

${ }^{5}$ Variables must be standardized such that variable selection does not depend on the measurement scale.
} 
variable can create a substantial omitted variable bias. Third, run OLS regression of outcome variable on the variable of interest, and the union of the sets of regressors chosen in the two LASSO runs. Then correct the inference with usual heteroscedasticity robust OLS standard error - the estimates of the response of outcome variable on the interest variable yield a causal interpretation.

\section{Results}

Our results are statistically significant at the $5 \%$ level of significance and are shown in Table 1 . The education channel is relevant to explain to some degree voting behavior. Legislators representing districts with a larger percentage of the population with bachelor's or higher degrees are more likely to vote in favor of abortion. As highlight by Wang and Buffalo (2004), a population with higher education attainment might be more likely to support abortion bills. Our results present a similar conclusion in which sectors such as information, scientific, management, professor, finance, and insurance, are positively associated with a higher likelihood of supporting the H.57 bill. Our results go a long way with the 2018 public opinion survey conducted by Pew Research Center; $71 \%$ of the U.S. college graduated or higher say abortion should be legal across the country. ${ }^{6}$

Corroborating Gohmann and Ohsfeldt (1990), legislators representing districts with larger voting female populations are more likely to support the bill in contrast to districts with more male voting population. Women are the ones that burden the most an unplanned pregnancy, and having the right to abort might alleviate this burden. We also find that districts with large unmarried partners are more likely to vote pro-choice, reflecting that women have acquired more control over the outcome of premarital sex Lundberg and Pollak (2007).

Finally, the poverty channel appears to impact the voting outcome. Legislators representing districts with a higher unemployment rate are more likely to vote pro-life. Our results are aligned with Strickland and Whicker (1992); authors suggest higher levels of per capita income is negatively related to regions' restrictiveness toward abortion.

\section{Conclusions}

In this paper, we take the Vermont legislature in passing the H. 57 bill, no restriction on an individual's right to abortion care across the entire gestation period, as a case to explain some of the determinants of expressive voting. The passing of the bill appears to not have changed the state's view toward abortion, creating a situation in which we can isolate the legislator voting behavior through the characteristics of the median voter in their district.

By employing high dimensional dataset and post-double-selection LASSO methodology, we find that median voter characteristics play an essential role in shaping legislator voting behavior. Poverty, gender, and population diversity are some crucial mechanisms that impact legislator voting behavior. Education and population diversity appear to influence legislators to vote pro-choice while the poverty rate is positively correlated with pro-life votes.

${ }^{6}$ See https://www.pewforum.org/fact-sheet/public-opinion-on-abortion/, accessed on July 4, 2019. 


\section{References}

Belloni, A., Chernozhukov, V., and Hansen, C. (2014). High-Dimensional Methods and Inference on Structural and Treatment Effects. Journal of Economic Perspectives, 28(2):29-50.

Copeland, C. and Laband, D. N. (2002). Expressiveness and Voting. Public Choice, 110(3):351-363.

Drinkwater, S. and Jennings, C. (2007). Who are the expressive voters? Public Choice, 132(1/2):179-189.

Gohmann, S. F. and Ohsfeldt, R. L. (1990). Predicting state abortion legislation from us senate votes: The effects of apparent ideological shirking. Review of Policy Research, 9(4):749-762.

Greene, K. V. and Nelson, P. J. (2002). If extremists vote how do they express themselves? an empirical test of an expressive theory of voting. Public Choice, 113(3/4):425-436.

Lundberg, S. and Pollak, R. A. (2007). The american family and family economics. In Journal of Economic Perspectives.

Medoff, M. H. (2002). The determinants and impact of state abortion restrictions. American Journal of Economics and Sociology, 61(2):481-493.

Schecter, D. (2001). What drives the voting on abortion policy? investigating partisanship and religion in the state legislative arena. Women $\&$ Politics, 23(4):61-83.

Strickland, R. A. and Whicker, M. L. (1992). Political and socioeconomic indicators of state restrictiveness toward abortion. Policy Studies Journal, 20(4):598-617.

Taylor, K. and Turkewitz, J. (2019 (accessed May 4, 2020)). Vermont Moves to Protect Abortion Rights as Other States Impose Bans. https://www.nytimes.com/2019/05/21/us/vermont-abortion-bill-h57.html.

Wang, G.-z. and Buffalo, M. (2004). Social and cultural determinants of attitudes toward abortion: A test of reiss' hypotheses. The Social Science Journal, 41(1):93-105. 
Figure 1: Trend of U.S. Abortions Rate

Numbers of abortion per 1,000 women aged 15-44

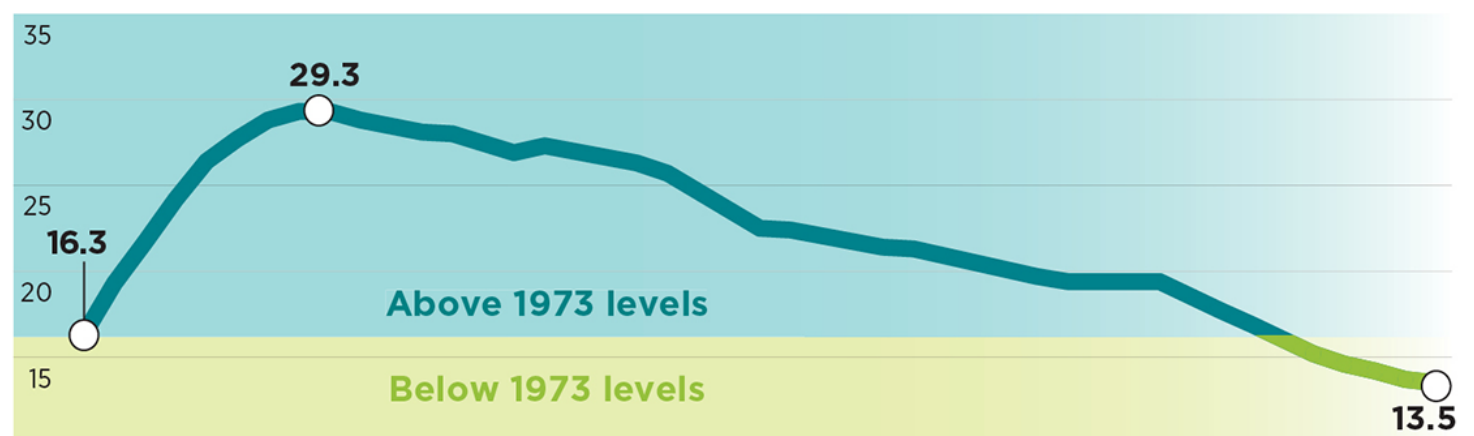

10

5

$\begin{array}{llllllllllll}1973 & 1977 & 1981 & 1985 & 1989 & 1993 & 1997 & 2001 & 2005 & 2009 & 2013 & 2017\end{array}$

Note: Source: https://data.guttmacher.org/states/trend?state=US\&topics=65\&dataset=data 


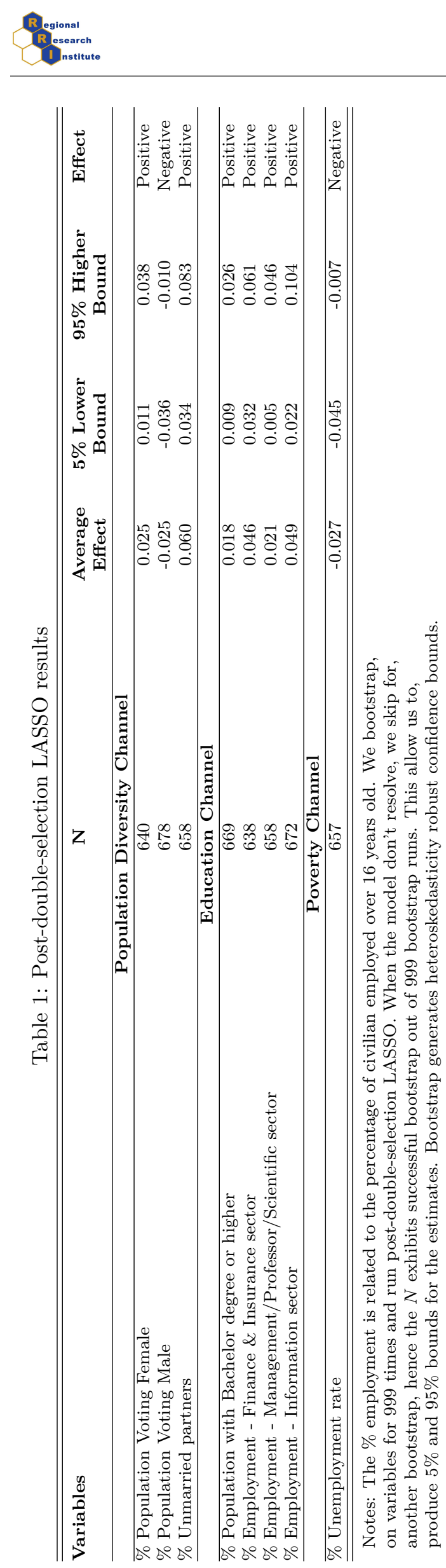

